\title{
O MÉTODO EM MARX
}

\author{
THE METHOD IN MARX \\ EL MÉTODO DE MARX
}

\begin{abstract}
Renata Machado de Assis
Professora Doutora da Universidade Federal de Goiás - Regional Jataí. Jataí-GO, Brasil.

renatafef@hotmail.com
\end{abstract}

RESUMO: Este artigo tem como objetivo apresentar um estudo realizado sobre o método em Marx, a partir de algumas de suas publicações e de outros autores que estudaram suas obras. A metodologia utilizada foi pesquisa bibliográfica, por meio de revisão teórica, utilizando os escritos deste autor e de outros. A análise das obras selecionadas permite depreender que os princípios defendidos por Marx se caracterizam na ideia de que a solução para os mistérios especulativos, para os problemas e contradições da ordem social, efetivamente existentes, deve ser buscada por meio de uma reorientação extrema do próprio pensamento, em contraste com as concepções filosóficas do passado, buscando uma forma de abordagem qualitativamente diferente, ou seja, toda investigação teórica deve se focar na prática transformadora relevante aos seus interesses. Para este autor, não importa apenas a interpretação, mas a transformação; e o método cientificamente exato é o último método. O concreto só o é porque sintetiza as múltiplas determinações, isto é, "unidade do diverso". Por isso o concreto é o processo da síntese, o resultado, e não o ponto de partida, ainda que o seja. Pode-se concluir que a proposta apresentada por Marx supera o dualismo sujeito e objeto na construção do conhecimento. O que ele propõe, é o método como um instrumento de mediação entre o homem que pretende conhecer e o objeto desconhecido, como parte da realidade a ser desvelada. A abstração utilizada pela dialética revela a essência além da aparência. O que importa é o que é abstrato, o que é imediado, ao contrário do que é mediado; é partir do simples para o complexo; do abstrato para o concreto; da parte para o todo; do singular para o universal.

PALAVRAS-CHAVE: Método. Materialismo histórico-dialético. Produção científica.

ABSTRACT: This article aims to present a study about the method in Marx, from some of his publications and other authors who studied his works. The methodology used was a bibliographical research, through theoretical revision, using the writings of this author and others. The analysis of the selected works allows us to understand that the principles defended by Marx characterised in the idea that the solution to the speculative mysteries, to the problems and contradictions of the social order, effectively existing, must be fetched of a reorientation of the extreme own thought, in contrast with the philosophical conceptions of the past, seeking a way to qualitatively different approach, that is, the total theoretical research must focus on the practical transforming relevant to their interests. For this author, not only important to the interpretation, but the transformation; and the scientifically accurate method is the last method. The concrete is only because it summarises the multiple determinations, that is, "unity of different". For this reason the concrete is the process of synthesis, the result and not the point of departure, that is still. It can be concluded that the proposal submitted by Marx surpasses the dualism subject and object in the construction of knowledge. What he proposes, is the method as an instrument of mediation between the man who wants to know and the unknown object, as part of the reality to be unraveled. The abstraction used by dialectic reveals the essence beyond the appearance. The important thing is what is abstract, what is imediated, contrary to what is mediated; is from simple to complex; of abstract for the concrete; the part for the whole; the singular to universal.

KEYWORDS: Method. Historical-dialectic materialism. Scientific production.

Artigo recebido em janeiro de 2017

Aprovado em março de 2017 
RESUMEN: Este artículo tiene como objetivo presentar un estudio sobre el método de Marx, de algunas de sus publicaciones y otros autores que han estudiado sus obras. La metodología utilizada fue la literatura, a través de revisión de la literatura, usando los escritos de este autor y otros. El análisis de las obras seleccionadas nos permite concluir que los principios defendidos por Marx caracteriza en la idea de que la solución a la especulación, a los misterios de los problemas y las contradicciones del orden social existente, eficazmente, debe buscarse por medio de una reorientación de la extrema pensamiento propio, en contraste con las concepciones filosóficas del pasado, en busca de una manera cualitativamente diferente enfoque, es decir, toda la investigación teórica debe centrarse en la transformación de prácticas relevantes para sus intereses. Para este autor, no sólo es importante para la interpretación, pero la transformación; y el método científicamente exacto es el último método. El hormigón es sólo porque resume las múltiples determinaciones, es decir, "la unidad de diferentes". Por esta razón, el hormigón es el proceso de síntesis, el resultado y no el punto de partida, sin embargo, quién es. Se puede concluir que la propuesta presentada por Marx supera el dualismo sujeto y objeto en la construcción del conocimiento. Lo que él propone, es el método como un instrumento de mediación entre el hombre que quiere saber y el objeto desconocido, como parte de la realidad de ser develado. La abstracción utilizados por la dialéctica revela la esencia más allá de la apariencia. Lo importante es lo abstracto, qué es imediado, contrariamente a lo que está mediado; es de simple a complejo de abstract para el hormigón; la parte por el todo; lo singular a lo universal.

PALABRAS CLAVE: Método. Materialismo histórico-dialéctico. Producción científica. 


\title{
1| INTRODUÇÃO
}

Este artigo apresenta um estudo realizado sobre o método em Marx, a partir de algumas de suas publicações e da análise que outros autores, citados no decorrer do texto, fizeram de suas obras. Para isso, foram utilizadas referências que enfocam a questão do método, especificamente. A metodologia utilizada foi pesquisa bibliográfica, por meio da revisão teórica.

Inicialmente, dois comentários são necessários, a partir do que pontua Mészáros (2009). O primeiro é que no campo da economia e da filosofia políticas, a determinação social do método na época do capital segue em direção totalmente contrária, ao eternizar as relações de troca do sistema do capital, estabelecidas historicamente e necessariamente transitórias em termos de época, assim como pelo culto do indivíduo isolado em consonância com esses elementos. E o segundo é que a reorientação marxiana do método põe em destaque a inseparabilidade dos aspectos metodológicos dos problemas encontrados em sua dimensão substantiva. Essa reorientação trata de como trazer à vida de modo pleno até mesmo os problemas mais complexos e abstratos, elucidando-os a partir da interdependência de suas dimensões fundamentais.

Os princípios defendidos por Marx se caracterizam na ideia de que a solução para os mistérios especulativos, para os problemas e contradições da ordem social, efetivamente existentes, deve ser buscada por meio de uma reorientação extrema do próprio pensamento, em contraste com as concepções filosóficas do passado. Na visão deste autor, é necessário buscar uma forma de abordagem qualitativamente diferente, ou seja, toda investigação teórica deve se focar na prática transformadora relevante aos seus interesses. Destarte, a ideia de unificar teoria e prática assume uma relevância fundamental na concepção marxiana do mundo e permanece como um de seus princípios orientadores vitais.

\begin{abstract}
Assim, o princípio orientador fundamental da concepção marxiana de ciência se converte em como assumir o controle sobre todos os aspectos do processo de reprodução social, desde aqueles diretamente envolvidos nas condições materiais básicas de existência da humanidade até as mais mediadas atividades artísticas teóricas e criativas da vida dos indivíduos sociais. Naturalmente, dado o caráter dinâmico dos problemas em questão, tanto em relação ao desenvolvimento humano da maneira como progrediu no passado quanto em relação à sua trajetória conscientemente planejada no futuro, a abordagem inteira precisava ser histórica de forma inevitável. Em contraste com as concepções filosóficas do passado não poderia haver dúvida sobre um desfecho histórico ideologicamente conveniente. (MÉSZÁROS, 2009, p. 213, grifo do autor).
\end{abstract}

No entender de Marx, os homens têm história porque eles têm que produzir sua vida, e precisam fazê-lo de modo determinado. Ele resumiu sua orientação metodológica dizendo que conhecemos uma única ciência, que é a ciência da história.

Para este autor, o ponto de vista do velho materialismo é o da sociedade civil, enquanto o ponto de vista do novo é o da sociedade humana, ou o da humanidade social. Na orientação marxiana de método, a relevância do ponto de vista que parte da sociedade civil não pode limitar-se ao antigo materialismo, pois, as filosofias idealistas especulativas são caracterizadas pelas mesmas limitações de ponto de vista. A crítica ao ponto de vista da sociedade civil é em função das contradições sociais antagônicas da ordem social estabelecida, com indivíduos egoístas. A ordem hierárquica social existente permaneceu além da crítica. A posição metodológica adotada pode cumprir, e de forma bem sucedida, sua função ideológica de racionalizar o existente, de modo plenamente conciliador. É por isso que Marx (1978a) afirma que a sociedade burguesa era contraditória, não de forma individual, mas no sentido de uma contradição que nasce das condições de existência social dos indivíduos, e as forças produtivas que se movem no seio da sociedade burguesa 
criam, ao mesmo tempo, as condições materiais para resolver esta contradição.

Mészáros (2009) contextualiza que, a partir das condições de aprofundamento da crise estrutural do sistema do capital, a condição vital de sucesso para o futuro é a elaboração de um modo qualitativamente diverso e não antagônico para mediar o metabolismo social. Nesse sentido, a preocupação com as questões do método apropriado para lidar com os graves problemas e dificuldades da época de transição histórica está, de forma íntima, relacionada a este tópico. Mas essa mediação qualitativamente nova não pode ser exagerada, pois se trata da mediação da relação entre natureza e humanidade, assim como entre os indivíduos. Segundo o autor, o ponto de partida necessário à reorientação do método, herdado do passado, "é submeter a uma crítica radical a modalidade estabelecida de mediação de reprodução social sob o domínio do capital” (MÉSZÁROS, 2009, p. 192).

Marx frisava que os filósofos apenas interpretaram o mundo de diferentes maneiras, e o que importa não é só a interpretação, mas a transformação, como explicitado na sua $11^{a}$ tese sobre Feuerbach, escrita em conjunto com Engels (MARX; ENGELS, 1984). A mudança qualitativa vislumbrada por Marx, "metodologicamente vital para a crítica da economia política como anatomia dos antagonismos estruturais da sociedade civil" (MÉSZÁROS, 2009, p. 197, grifo do autor), foi sintetizada por ele como o estabelecimento necessário do sistema de produção e distribuição, por meio do qual o círculo vicioso da mediação antagônica poderia ser rompido e trocado por uma nova forma de mediação comunal não antagônica.

\begin{abstract}
A esse respeito a questão central refere-se à forma específica de mediação por meio da qual a estrutura hierárquica da divisão do trabalho, sob o domínio do capital, poderia abrir caminho para o modo de reprodução diretamente social da "nova forma histórica". Em outras palavras, refere-se ao estabelecimento dos parâmetros e a direção na qual - nas palavras de Marx - "no lugar de uma divisão do trabalho" (cujos imperativos materiais são impostos sem cerimônias sobre os sujeitos do trabalho) a atividade vital conscientemente autocontrolada dos indivíduos sociais poderia ser integrada em uma totalidade produtivamente viável e humanamente realizadora. (MÉSZÁROS, 2009, p. 197, grifo do autor).
\end{abstract}

O destaque, portanto, é para o estabelecimento, em termos históricos, de uma nova mediação do intercâmbio metabólico da espécie humana com a natureza e da atividade produtiva autodeterminada progressivamente entre os indivíduos da sociedade. É sobre a forma de conhecer esta realidade, sobre este método defendido por Marx, que se pretende discorrer, neste artigo, com a consciência da evidência de que o marxismo ainda é uma estrutura de pensamento vital e de continuidade ininterrupta desde o tempo de sua produção.

\title{
2| SOBRE O MÉTODO EM MARX
}

Antes de discorrer sobre o que Marx apresenta a respeito do método, que é o foco deste estudo, torna-se relevante contextualizar, de certa forma, essa temática.

McLellan (1983) pontua que somente com a obra Ideologia Alemã, escrita em conjunto com Engels, é que Marx chegou à concepção materialista da história, que se tornou o eixo condutor de todos os seus estudos posteriores. Ele, então, se empenhou no sentido de esclarecer sua própria concepção. Durante os dez anos anteriores, as produções de Marx se desenvolveram em sucessivas fases, passando pelo idealismo romântico, o idealismo hegeliano e o racionalismo liberal, até a elaboração de ampla crítica à filosofia hegeliana. No entender de McLellan (1983), a concepção materialista de história tracejada na Ideologia Alemã e as hipóteses econômicas formuladas na Miséria da Filosofia constituíram, portanto, a base teórica da ação política de Marx. Segundo 
Vilar (1983), foi em Ideologia Alemã que o problema da história como ciência foi verdadeiramente enfrentado: Marx afirmou conhecer uma única ciência: a ciência da história.

Para Marx, deveria ser pensada uma teoria adequada, como elemento integrante da unidade entre teoria e prática: uma concepção dialética. Para isso, ele se recusou a tomar como modelo da filosofia as ciências naturais, as quais ele considerava abstratamente materiais, e que separavam a teoria da prática, além de fragmentá-las e contrapô-las entre si, em vez de trabalhar de forma unitária com ambas. Então, Marx tinha a compreensão de que o aspecto subjetivo do problema tinha de ser integrado por uma concepção dialética do desenvolvimento histórico real, e não ser considerado individualmente; e de que deveria haver a reconstrução da teoria na unidade de teoria e prática e na superação da divisão social do trabalho (praxis social).

A tese de que "o modo de produção da vida material condiciona o processo da vida social, política e espiritual em geral", de que todas as relações sociais e estatais, todos os sistemas religiosos e jurídicos, todas as idéias teóricas que aparecem na história só podem ser compreendidos quando tiverem sido compreendidas as condições materiais de vida da época de que se trata, e se tenha sabido explicar tudo aquilo por estas condições materiais; esta tese era uma descoberta que vinha revolucionar não só a economia, mas todas as ciências históricas (e tôdas as ciências que não são naturais são históricas). (ENGELS, [19-], p. 305-306, grifo do autor).

A tese, de aparência tão simples, de que a consciência do homem depende de sua existência, e não o contrário, rejeita todo idealismo, mesmo o mais dissimulado. Então, o problema que se apresentou, foi com qual método deveria tratar-se a ciência. Segundo Engels ([19-], p. 309), de um lado estava a dialética de Hegel, de forma abstrata e especulativa; e de outro o método ordinário, em sua essência metafísica, wolffiano. Este último modelo foi destruído teoricamente por Kant e por Hegel, e lutava para subsistir na prática; e o primeiro "partia do nada, para chegar ao nada, a partir do nada".

O que punha o modo de pensamento hegeliano acima dos outros era o sentido histórico que o animava. Mas a concepção de história presente neste método é que fez a premissa teórica direta da nova concepção materialista. Empreender a crítica a ele, portanto, não era coisa fácil, e a esta tarefa Marx se entregou.

\footnotetext{
Mesmo depois de descoberto o método, e de acordo com ele, a crítica da economia política podia ser empreendida de dois modos: o histórico e o lógico. Como na história, do mesmo modo que no seu reflexo literário, as coisas se desenvolvem, também, a grandes traços, do mais simples para o mais complexo [...]. A história se desenvolve com freqüência aos saltos e em ziguezagues, e seria preciso acompanhá-la, assim, em toda a sua trajetória [...]. Ademais, a história da economia política não poderia ser escrita sem a da sociedade burguesa [...]. Portanto, o único método indicado era o lógico. Mas este não é, na realidade, senão o método histórico, despojado apenas da sua forma histórica e das contingências perturbadoras. (ENGELS, [19-], p. 310).
}

Neste método, parte-se sempre do mais simples que existe historicamente, de fato; logo se inicia sua análise. No simples fato de se tratar de uma relação já fica implícito que há dois lados que se relacionam, de onde se depreende sua relação recíproca e sua interação. Os fatos reais ocorrem, real e efetivamente, então não seguem um processo abstrato de pensamento. Os fatos continuam ocorrendo, e as contradições que surgem na prática também terão encontrado sua solução, que por sua vez cria uma nova relação, e cujos lados contrapostos precisam ser desenvolvidos em seguida, e assim sucessivamente. Portanto, com esse método, o desenvolvimento lógico não é obrigado a se mover no campo do puramente abstrato. "Pelo contrário, precisa ilustrar-se com exemplos históricos, manter-se em contato constante com a realidade" (ENGELS, [19-], p. 312). 
Marx e Engels (1984) afirmam que toda historiografia deve partir das bases naturais, e que sua modificação no decorrer da história depende da ação humana. Por conseguinte, os homens produzem os seus meios de vida, e ao fazerem isso, produzem indiretamente a sua própria vida material. Aquilo que são, coincide com o que e como produzem, ou seja, depende das condições materiais da sua produção. E essa produção só ocorre com o aumento da população. Este é um modo concebível de cumprir de forma bem-sucedida a tarefa histórica, de consolidação do sistema comunal de produção e consumo, em sua inseparabilidade dialética recíproca, como defendido por Marx.

Nenhuma forma social, em qualquer que seja o nível de complexidade, é concebível sem alguma forma de relação de troca. O termo social é, em certo sentido, sinônimo disso. No entanto, o problema que se apresenta é que as relações de troca, sob o domínio do capital, estão sujeitas à opressão da lei do valor. As conseqüências disso são alienantes e constrangedoras para os seres humanos, como a dependência dos valores de uso para satisfazer seus anseios e a necessidade capitalista imposta à produção de valores de troca que produzem lucros.

Em sua obra, Marx e Engels (1984, p. 23) defendem que a produção das idéias, das representações e da consciência está, a princípio, diretamente entrelaçada com a atividade e o intercâmbio material dos homens, com a linguagem da vida real. "Não é a consciência que determina a vida, é a vida que determina a consciência." Destarte, a história deixa de ser um conjunto de fatos mortos, como é para os empiristas, ou uma ação imaginada, de sujeitos também imaginados, como para os idealistas". "Todo o movimento da história é pois, como sua real geração - o nascimento de sua existência empírica, - igualmente para sua consciência pensante o movimento compreendido e consciente de sua realização" (MARX, 1963, p. 24, grifo do autor).

A concepção materialista da história, portanto, para Marx, assenta-se no desenvolvimento do processo real da produção, partindo da produção material da vida imediata, e na concepção da forma de intercâmbio ligada a este modo de produção e por ele produzida. Esta concepção de história explica as formações de ideias a partir da praxis material. Em suas teses sobre Feuerbach², Marx e Engels (1984) afirmam que a insuficiência de todo o materialismo é a de a realidade ser tomada apenas sob a forma do objeto ou da contemplação, mas não como atividade humana sensível, praxis. Para eles, é na prática que o homem deve comprovar a verdade. Toda a vida social é essencialmente prática, e a solução racional a todos os mistérios se encontra na praxis humana e no compreender desta praxis.

A concepção materialista da história, portanto, para Marx, assenta-se no desenvolvimento do processo real da produção, partindo da produção material da vida imediata, e na concepção da forma de intercâmbio ligada a este modo de produção e por ele produzida. Esta concepção de história explica as formações de ideias a partir da praxis material. Em suas teses sobre Feuerbach , Marx e Engels (1984) afirmam que a insuficiência de todo o materialismo é a de a realidade ser tomada apenas sob a forma do objeto ou da contemplação, mas não como atividade humana sensível, praxis. Para eles, é na prática que o homem deve comprovar a verdade. Toda a vida social é essencialmente prática, e a solução racional a todos os mistérios se encontra na praxis humana e no compreender desta praxis.

Para Marx (1978a, p. 14, grifo do autor), "o homem é o objeto imediato da ciência natural; [...]. Mas a natureza é o objeto imediato da ciência do homem". O homem só pode encontrar na ciência

\footnotetext{
${ }^{1}$ Para Marx e Engels (1984), o empirismo materialista considera a realidade objetiva como última fonte da experiência sensorial, e vê no conhecimento um reflexo da realidade objetiva. E o materialismo idealista limita a experiência às sensações e as toma, portanto, como realidade objetiva.

2 Segundo McLellan (1983, p. 86), Engels corretamente definiu as Teses sobre Feuerbach como "o primeiro documento no qual está depositado o germe genial da nova concepção do mundo".
} 
da natureza o seu próprio conhecimento. Para o homem socialista, toda a produção universal nada mais é do que a produção do homem por via do trabalho humano - essencialidade do homem na natureza. Em outra obra (MARX, 1963, p. 36, grifo do autor), o autor afirma que todas as etapas de cultura do homem podem ser apreciadas a partir dessa relação (homem-natureza).

O homem é o objeto imediato das ciências naturais, porque a natureza sensível imediata é, para o homem, a materialidade humana (expressão idêntica), de maneira mais imediata do que o outro homem que existe materialmente para ele; porque a sua própria materialidade só existe pelo outro homem, para êle, como materialidade humana. Mas a natureza é o objeto imediato da ciência que trata do homem.

O próprio elemento da manifestação da vida, segundo Marx (1963), é de natureza material: a linguagem. A ciência só aparece, no tempo e na realidade, quando o espírito assume a consciência de si próprio. E a relação de tempo nada mais é do que história. A representação objetiva terminada é ao mesmo tempo a reflexão da substância ou a transformação dessa mesma substância no eu. E a ciência é o verdadeiro saber que o espírito possui de si mesmo.

No entender de Marx (1978b), o método cientificamente exato é o último método. O concreto só o é porque sintetiza as múltiplas determinações, isto é, unidade do diverso. Por isso o concreto é o processo da síntese, o resultado, e não o ponto de partida, ainda que o seja.

Para Marx (1988), deve-se distinguir o método de exposição formal do método de pesquisa. A pesquisa capta detalhadamente a matéria, analisa suas formas variadas de execução e rastreia sua conexão íntima. No interior do conteúdo analisado só pode subsistir aquilo que foi compreendido de forma adequada. Para o autor, expor de forma correta significa utilizar uma teoria das abstrações racionais, de apropriação e de captação do ser objetivo, conforme suas particularidades. Somente após finalizado este trabalho é que se pode expor de forma adequada o movimento real. Na sua concepção, o seu método dialético, por sua fundamentação, não só difere-se do hegeliano, como é sua antítese direta.

Para Hegel, o processo de pensamento, que ele, sob o nome de idéia, transforma num sujeito autônomo, é o demiurgo do real, real que constitui apenas a sua manifestação externa. Para mim, pelo contrário, o ideal não é nada mais que o material, transposto e traduzido na cabeça do homem. (MARX, 1988, p. 27).

O autor comenta que, no início, durante a elaboração do primeiro capítulo de O Capital, confessou-se abertamente discípulo de Hegel, e concebe que este pensador foi o primeiro a expor as suas formas gerais de movimento, de maneira ampla e consciente, mistificando a dialética. $\mathrm{E}$ a dialética foi moda alemã porque ela parecia sublimar o existente (MARX, 1988). No entanto, afastou-se das idéias de Hegel, apesar de seu completo reconhecimento das grandes conquistas da dialética hegeliana. Sua crítica a Hegel é centrada em dois pontos, que foram, de forma clara, sintetizados por Mészáros (2009): 1) a fusão hegeliana das categorias de objetivação e alienação, tendenciosamente ofuscando a natureza desta; e 2) a abstração especulativa e reconciliadora por parte de Hegel dos problemas práticos vitais e das contradições do mundo realmente existente. Para Marx (1988), a dialética de Hegel está de cabeça para baixo, e torna-se necessário colocá-la de cabeça para cima, para que se possa descobrir a substância racional dentro da cártula mística.

Marx (2009) afirma que a metafísica, a filosofia inteira, se resume no método, segundo o pensamento de Hegel. Então ele aponta sete observações sobre o que foi escrito pelo Sr. Proudhon, em caráter de contestação, das quais se pode retirar a essência da discussão de Marx sobre o método. Cabe ressaltar que Marx criticou os teóricos que insistiram em construir categorias fechadas, como é o caso das teses do Sr. Proudhon. 
Na primeira observação, Marx (2009) questiona o mundo das categorias lógicas, posto pela metafísica, em que há redução de qualquer conjunto de produtos e de produção, de objetos e de movimento a uma metafísica aplicada. Neste método, segundo o autor, há abstração e não análise (o que aparece é uma categoria lógica). "Tudo o que existe, tudo o que vive sobre a terra e sob a água, existe e vive graças a um movimento qualquer. Assim, o movimento da história produz as relações sociais, o movimento industrial nos proporciona os produtos industriais, etc" (MARX, 2009, p. 122). E dessa mesma forma, é possível transformar todas as coisas em categorias lógicas, pela força da abstração, ou seja, "basta-nos somente abstrair todo caráter distintivo dos diferentes movimentos para chegar ao movimento em estado abstrato, ao movimento puramente formal, à formula puramente lógica do movimento" (MARX, 2009, p. 123).

Mas se, segundo Marx (2009), citando Hegel, encontra-se nas categorias lógicas a substância de todas as coisas, imagina-se encontrar a fórmula lógica do movimento no método absoluto, que ao mesmo tempo explica as coisas e implica o movimento delas.

Mas o que é esse método absoluto? A abstração do movimento. E o que é a abstração do movimento? O movimento em estado abstrato. O que é o movimento em estado abstrato? A fórmula puramente lógica do movimento ou o movimento da razão pura. Em que consiste o movimento da razão pura? Consiste em se pôr, se opor, se compor, formular-se como tese, antítese, síntese ou, ainda, afirmar-se, negar-se, negar sua negação. (MARX, 2009, p. 123).

A razão, ao conseguir se colocar como tese, esta tese, este pensamento, oposto a si mesmo, desdobra-se em pensamentos contraditórios: o sim e o não, o positivo e o negativo. A luta entre esses elementos antagônicos constitui o movimento dialético (compreendido na antítese). Os contrários se equilibram, paralisam, neutralizam e se fundem, constituindo um pensamento novo, que é a sua síntese. Por sua vez, esse novo pensamento se desdobra ainda em dois outros pensamentos contraditórios, e se fundem em outra síntese. Desse processo nasce um grupo de pensamentos que segue a mesma oscilação dialética de uma categoria simples, e tem um grupo contraditório por antítese. Então nasce um novo pensamento, que é a síntese, destes dois grupos citados. "Assim como do movimento dialético das categorias simples nasce o grupo, do movimento dialético dos grupos nasce a série e do movimento dialético das séries nasce todo o sistema" (MARX, 2009, p. 124). Sob o ponto de vista de Marx, a dialética é a manifestação da razão que se concretiza sob a força da efetividade material; é o aparecimento do resultado, o surgimento em processo que se põe como o ato de produção real. A dialética caracteriza-se em método de exposição e em movimento efetivo do conteúdo. Ela se resume na demonstração metódica do movimento da matéria, cujo conteúdo só será compreendido caso sua maturidade o permita. Tanto o objeto quanto o pensamento precisam estar em conformidade com a cientificidade do método. $O$ método dialético, na acepção do autor, permite reconhecer a historicidade do modo de produção capitalista, incluindo suas contradições, e capta sua tendência de decomposição e transformação em outra forma de sociedade.

Na segunda observação, Marx (2009) comenta que as categorias econômicas são expressões teóricas, são abstrações das relações de produção. Além da mercadoria, o homem produz e determina também as relações sociais, intimamente ligadas às forças produtivas. $O$ homem adquire novas forças produtivas e transforma seu modo de produção, alterando a forma de ganhar a vida, ou seja, ele transforma todas as suas relações sociais.

Este mesmo homem que estabelece as relações sociais de acordo com a sua produtividade material, também produz os princípios, idéias, categorias, de acordo com suas relações em sociedade. Assim, essas categorias são produtos históricos e transitórios, tão pouco eternas quanto as relações que exprimem. De imutável só existe a abstração do movimento. 
Na terceira observação, o autor diz que as relações de produção de qualquer sociedade constituem um todo. No corpo social, todas as relações coexistem simultaneamente, sustentando-se mutuamente. Portanto, todas essas relações sociais devem ser engendradas no movimento dialético, com simultaneidade das fases.

Na quarta observação, Marx (2009) esclarece que na dialética de Hegel não existem dois lados - um bom e um mal. Ele não tem problemas a colocar e nem a resolver. Apenas possui a dialética, pois o que constitui o movimento dialético é a coexistência de dois lados contraditórios, sua luta e sua fusão numa categoria nova.

Na quinta observação esta posição é reforçada: a partir do momento em que o processo dialético se reduz à simples oposição do bem ao mal, de colocar problemas destinados à extirpação do mal e de apresentar uma categoria como antídoto da outra, a partir desse momento as categorias perdem sua espontaneidade. Neste caso, a dialética não é mais a expressão e o movimento da razão absoluta.

Na sexta observação, o autor diz que, com todas as eternidades imutáveis e imóveis, não há história; "há, no máximo, a história na idéia, ou seja, a história que se reflete no movimento dialético da razão pura" (MARX, 2009, p. 132). E ainda, "a razão humana não cria a 'verdade', oculta nas profundezas da razão absoluta, eterna; pode apenas desvelá-la" (MARX, 2009, p. 133, grifo do autor). Mas as verdades desveladas até hoje são incompletas, insuficientes e, por esse motivo, contraditórias.

Na sétima e última observação, Marx (2009) afirma que os economistas são representantes científicos da classe burguesa, assim como os socialistas e os comunistas são os teóricos da classe operária. Enquanto o proletariado não se constitui como classe e sua própria luta contra a burguesia não tem caráter político, e enquanto as forças produtivas ainda não estão desenvolvidas o suficiente no seio da burguesia, para possibilitar uma antevisão das condições necessárias à libertação do proletariado e à formação de uma nova sociedade, "esses teóricos são apenas utopistas que, para amenizar os sofrimentos das classes oprimidas, improvisam sistemas e correm atrás de uma ciência regeneradora" (MARX, 2009, p. 141). No entanto, à medida que a história avança, e que a luta do proletariado se desenha mais claramente, eles não carecem mais de procurar a ciência em seu espírito: basta-lhes se conscientizar do que se passa ante seus olhos e se tornarem os mensageiros disso. "Enquanto procuram a ciência e apenas formulam sistemas, enquanto se situam nos inícios da luta, eles vêem na miséria somente a miséria, sem observarem nela o lado revolucionário, subversivo, que derrubará a velha sociedade" (MARX, 2009, p. 142). $\mathrm{Na}$ opinião do autor, a ciência produzida pelo movimento histórico deixa de ser doutrinária e se torna revolucionária.

A proposta apresentada por Marx supera o dualismo sujeito e objeto na construção do conhecimento. Ele propõe o método como um instrumento de mediação entre o homem que pretende conhecer e o objeto desconhecido, como parte da realidade a ser desvelada.

Em sua relação com a natureza, o homem procura a satisfação de suas necessidades. Esse contato é incorporado à sua vida, e orienta outras atividades, levando-o a intervir sobre sua realidade, conhecendo-a e transformando-a. Destarte, a vida em sociedade se constrói como processo histórico, e não como conseqüência imediata da imposição da natureza. O homem constrói, então, sua historicidade, que sofre influência das condições materiais que lhe são postas, das conquistas e transformações obtidas e acumuladas, e das relações sociais estabelecidas.

A realidade, para Marx, é o ponto de partida e o ponto de chegada. É a partir da relação do homem com o mundo que a ciência se constrói, que o objeto pode ser conhecido. O próprio percurso do objeto coloca o conhecimento junto com o desenvolvimento do ser, pois na dissolução das determinações desse objeto, o que se observa e se compreende como produto da formação 
é o método como o próprio fluir do conteúdo. Marx (1988) apresenta, na obra O Capital, a determinação do objeto já posto, específico e sintético, e a particularidade das categorias é que levam a esta configuração. No seu entender, a pesquisa permite acessar as mediações do objeto que levarão à identificação das categorias. Parte-se da representação para a elaboração do conceito (categorias). A categoria é que determina a ordem das mediações, a da organização.

No que se refere ao locus da pesquisa, Marx (1978b; 1988) procurava investigar seu objeto onde ele se encontrava mais desenvolvido. O fenômeno se manifesta com menor grau de exterioridades, no local em que ele se encontra mais desenvolvido. As realidades mais complexas, em sua opinião, contêm as mais simples.

Marx (1978b) enfatiza que parte da realidade concreta, e não de ideias pré-concebidas ou da especulação. Para ele, o importante é tomar a aparência da realidade, para buscar nela o que é a essência, e desinverter as inversões, que estão na representação, para entender o conceito. Porém, para compreender os nexos de dada realidade, é preciso utilizar a abstração. A abstração utilizada pela dialética revela a essência além da aparência. O que importa é o que é abstrato, o que é imediado, ao contrário do que é mediado; é partir do simples para o complexo; do abstrato para o concreto; da parte para o todo; do singular para o universal. Para Marx, a realidade é falsa, mas existe (é real): o que é visível e concreto, realmente existe, é evidente do ponto de vista empírico. Mas a captação da realidade tal qual ela se apresenta, é a captação da essência, do abstrato. Desta forma, o objeto é tão complexo que cada um o conhece de uma forma. O conhecimento científico se opõe ao fetichismo, pois busca conhecer as mediações do objeto no sentido de conhecê-lo desfetichizado.

\section{3 | ALGUMAS CONSIDERAÇÕES}

À guisa de conclusão, pode-se apresentar uma síntese do conteúdo exposto sobre o método marxiano, apontando o essencial dessa tentativa de sistematização, com breves complementações.

O método considerado correto, por Marx, visa identificar o que se oculta na realidade como uma verdade falsa. O que ele compreendia era que, na aparência imediata, a realidade se apresentava opaca. Desta forma, havia a necessidade de um método científico que revelasse o que se esconde nesta realidade. O princípio explicativo do método marxiano, conforme o próprio autor defende, é a contradição, pois nele se expressa uma epistemologia compreensiva, e não explicativa.

Pode-se dizer que o objetivo deste método é construir categorias mediadas. As categorias compreendem os nexos constitutivos da realidade; são lógicas, por serem mediadas pela ideia; são históricas, por nelas se expressar a realidade; e essas categorias não têm correspondência empírica na realidade posta, visto que a realidade não se apresenta com transparência.

Para Marx, categorias são expressões lógicas da realidade. É a organização teórica, síntese teórica de mediações que permitem conhecer a realidade, como por exemplo, em suas obras, a categoria do capital, a categoria de mercadoria, dentre outras. Na construção das categorias é importante que se distinga a representação do conceito, como ele defende. Ao construir um conceito, inicialmente se investiga as representações, que são submetidas a um processo de abstração e que, enfim, encontra suas determinações. A representação demonstra o aparente sem mediações. Já o conceito é mais amplo, pois inclui as mediações.

O papel da ciência, para Marx, é desenvolver um procedimento racional que busque compreender o que está oculto na realidade. A realidade imediata é uma ilusão, pode ser real e falsa simultaneamente. Cabe à ciência captar o que está obscuro no objeto, identificando os nexos internos constitutivos da realidade. 
O conhecimento da realidade, para Marx, deveria ser extraído da praxis, da materialidade do fenômeno e não apenas das idéias. A descrição dos fatos, da realidade em si, não é ciência, e sim ideologia. E para o autor, a verdadeira ciência é completamente contra qualquer tipo de ideologia e senso comum.

O método é, na concepção de Marx, a explicitação da divisão do objeto em dois níveis: no que se refere às suas articulações interiores e particulares; e no que se refere à captação e desenvolvimento desse movimento nas especificidades do objeto, o que leva à definição de conceitos no interior do discurso do método. "A dialética aparece como o desenvolvimento do conceito de capital; a exposição como a crítica da contradição interior desse mesmo conceito com base em sua contradição fundamental - o trabalho enquanto potência subjetiva efetivadora do capital" (RANIERI, 1997/1998, p. 154).

O objeto de pesquisa, concebido por Marx, é o modo de produção capitalista e seus correspondentes na produção e na circulação. Para compreendê-lo, Marx busca as mediações que o constitui. Portanto, o objeto é estudado em sua historicidade. O autor busca o passado, e não apenas o tempo presente, para compreender o seu objeto de pesquisa.

Para Marx, o percurso que institui a verdade para o procedimento do pensamento, é o percurso que vai do mais simples para o mais complexo, ou seja, que parte do abstrato e chega ao concreto. E o concreto é entendido por Marx como a unidade do múltiplo, ou seja, é concreto porque é síntese de múltiplas determinações. Portanto, o pensamento aparece não como um ponto de partida, mas como um processo de síntese, como um resultado. Em outras palavras, no entender de Ranieri (1997/1998, p. 155), citando Marx, "o interesse metodológico é apontar para o fato de que a verdade não está inscrita no concreto imediato, mas na forma segundo a qual ela se constituiu em concreto mediatizado: a verdade mostrando-se como aquilo que corresponde à definitiva efetividade do concreto." Não é a imediatez que define a complexidade do objeto, e sim a decomposição dos elementos que perfizeram seu singular, durante o percurso, e que precisam ser reconhecidos segundo sua singularidade. Apenas na decomposição dos elementos, que são abstratos e objetivantes, é que se recompõe o pensamento como resultado do processo.

Enfim, alguns pontos principais podem ser destacados, nessa discussão sobre o método em Marx, e que sintetizam o compromisso da reflexão científica, a partir de suas colocações:

a) é importante que se apanhe os nexos internos, e não a superficialidade do objeto;

b) o elemento da naturalização das relações históricas é o elemento natural das relações sociais, pois do ponto de vista ideológico, o que é histórico é natural;

c) na investigação de dada realidade, deve-se revelar o que está oculto; o compromisso da ciência é revelar o que se esconde;

d) a verdade científica surge da elaboração teórica das relações, e a expressão teórica da realidade é a categoria. A categoria é tão eterna quanto sejam as relações sociais que lhe dão origem.

Em suas obras, Marx deixa claro que as leis gerais da vida econômica não são sempre as mesmas, pois cada período histórico constitui suas próprias leis, e a mudança de um período inicia um processo dirigido por novas leis, que determinam a vida em sociedade. Diante dessa realidade, e com a crítica, o sujeito pode ser capaz de transformar o conjunto das relações sociais. E mais importante do que compreender a realidade, no seu entender, é poder mudá-la. 


\section{Referências}

ENGELS, F. A "contribuição à crítica da economia política" de Marx. In: MARX, K.; ENGELS, F. Obras escolhidas. São Paulo: Editora Alfa Omega, [19-], p. 304-312. v. 1.

MARX, K. H. Economia política e filosofia. Rio de Janeiro: Editora Melso Soc. Anônima, 1963.

Manuscritos econômico-filosóficos. In: Manuscritos econômico-filosóficos e outros textos escolhidos. 2. ed. São Paulo: Abril Cultural, 1978a. p. 01-48. (Coleção Os Pensadores).

Miséria da filosofia: resposta à filosofia da miséria, do Sr. Proudhon. São Paulo: Expressão Popular, 2009.

O capital: crítica da economia política. 3. ed. São Paulo: Nova Cultural, 1988. v. 1.

Para a crítica da economia política. In: Manuscritos econômico-filosóficos e outros textos escolhidos. 2. ed. São Paulo: Abril Cultural, 1978b. p. 101257. (Coleção Os Pensadores).
MARX, K. H.; ENGELS, F. A ideologia alemã: teses sobre Feuerbach. São Paulo: Centauro, 1984.

McLELLAN, D. A concepção materialista da história. In: HOBSBAWN, E. J. (Org.). História do marxismo: o marxismo no tempo de Marx. Rio de Janeiro: Paz e Terra, 1983. p. 67-89. v. 1.

MÉSZÁROS, I. Estrutura social e formas de consciência. São Paulo: Boitempo Editorial, 2009.

RANIERI, J. J. Notas a respeito da concepção marxiana de método presente nos Grundrisse. Perspectivas: Revista de Ciências Sociais, São Paulo, v. 20/21, p. 151169, 1997/1998.

VILAR, P. Marx e a história. In: HOBSBAWN, E. J. (Org.). História do marxismo: o marxismo no tempo de Marx. Rio de Janeiro: Paz e Terra, 1983. p. 91-126. v. 1. 